\title{
Potencial Antimicrobiano do Extrato da Casca de Jabuticaba (Myrciaria cauliflora) Sobre Bactérias Gram Positivas e Negativas
}

Juliana Cristina Baldin (I), Karen Cristina Collograi (I), Euder Cesar

Michelin (I), Silvia Helena Seraphin Godoy (I), Raul Pereira Fregonesi (I), Volnei Brito Souza (I), Carmen Silvia Fávaro Trindade (I), Andrezza Maria Fernandes (I), Marco Antonio Trindade (I) (I) USP FZEA - Universidade de São Paulo - Fac de Zoot e Eng de Alimentos (Av. Duque de Caxias Norte, 225 Campus da USP CEP 13635-900 Pirassununga/SP)

\section{Resumo}

Com a intensa utilização de antibióticos e a possibilidade de resistência bacteriana, produtos naturais são estudados como alternativas, como o uso de extrato de plantas. A jabuticaba (Myrciaria cauliflora) possui potencial antimicrobiano devido às antocianinas, compostos fenólicos presentes nas suas cascas e sementes. Este trabalho teve como objetivo avaliar a atividade antimicrobiana in vitro do extrato aquoso de jabuticaba sobre bactérias gram positivas e negativas. Para a obtenção do extrato, foi realizado o despolpamento, obtendo-se o resíduo (casca e semente). A extração do pigmento foi realizada com adição de água na proporção de 1:3, na ausência de luz e sob agitação por 6 horas. O fluido obtido foi filtrado e o extrato bruto concentrado a $1 / 3$ de seu volume inicial utilizando um evaporador rotativo a $60^{\circ} \mathrm{C}$ acoplado a uma bomba de vácuo. Foram avaliadas cepas Gram positivas: Bacillus subtillis ATCC 6623, Bacillus cereus ATCC 14579, Staphylococcus aureus ATCC 6538, Staphylococcus aureus ATCC 14458, Staphylococcus aureus ATCC 43300, Staphylococcus aureus ATCC 29213 e Staphylococcus aureus ATCC 25923, e cepas Gram negativas: Salmonella enteritides ATCC, 13076, Escherichia coli ATCC 25922 e Pseudomonas aeruginosa ATCC 15442. O teste de difusão em ágar foi efetuado de acordo com a norma NCCLS M7-A6, com modificações,

\footnotetext{
Referência:

Juliana Cristina Baldin, Karen Cristina Collograi, Euder Cesar Michelin, Silvia Helena Seraphin Godoy, Raul Pereira Fregonesi, Volnei Brito Souza, Carmen Silvia Fávaro Trindade, Andrezza Maria Fernandes, Marco Antonio Trindade. Potencial Antimicrobiano do Extrato da Casca de Jabuticaba (Myrciaria cauliflora) Sobre Bactérias Gram Positivas e Negativas. In: Anais do 12 Congresso Latinoamericano de Microbiologia e Higiene de Alimentos - MICROAL 2014 [= Blucher Food Science Proceedings, num.1, vol.1]. São Paulo: Editora Blucher, 2014.

DOI $10.5151 /$ foodsci-microal-282
} 
testando as concentrações de 10, 25, 50, 80 e 100\% do extrato. Para determinação da concentração inibitória mínima (CIM), foi efetuada microdiluição em placas estéreis de 96 poços. Foram observadas zonas de inibição, com a formação de halos que variaram de 13 a $30 \mathrm{~mm}$ para as bactérias gram positivas e 15 a $26 \mathrm{~mm}$ para as bactérias gram negativas. Os valores obtidos para CIM foram de 1,57 g/L para B. subitillis, 3,13 g/L para B. cereus, $6,25 \mathrm{~g} / \mathrm{L}$ para $\mathrm{S}$. aureus $6538,3,13 \mathrm{~g} / \mathrm{L}$ para $\mathrm{S}$. aureus 14458 , $6,25 \mathrm{~g} / \mathrm{L}$ para $\mathrm{S}$. aureus $43300,12,5 \mathrm{~g} / \mathrm{L}$ para $\mathrm{S}$. aureus $29213,6,25 \mathrm{~g} / \mathrm{L}$ para S. aureus $25923,3,13 \mathrm{~g} / \mathrm{L}$ para S. enteritides, $6,25 \mathrm{~g} / \mathrm{L}$ para E. coli e $6,25 \mathrm{~g} / \mathrm{L}$ para $\mathrm{P}$. aeruginosa. Pode-se comprovar a eficiência do extrato de jabuticaba para todas as bactérias testadas, comprovando o potencial antimicrobiano do extrato, sendo que as gram positivas apresentaram os menores valores de CIM.

Palavras-Chave: Concentração inibitória mínima, Inibição, Difusão em disco

Agência de Fomento: FAPESP 